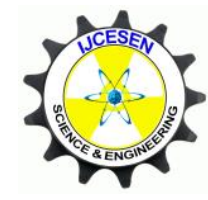

Copyright (C) IJCESEN
International Journal of Computational and

Experimental Science and $\boldsymbol{E N g i n e e r i n g}$

(IJCESEN)

Vol. 5-No.3 (2019) pp. 105-111

http://dergipark.gov.tr/ijcesen

Research Article

\title{
Experimental Investigation of Surface Roughness of Cutting Parameters in T6 Aluminum Alloy Milling Process
}

\author{
Neslihan ÖZSOY \\ Sakarya University, Engineering Faculty, Mechanical Engineering Department, 32200, Sakarya-Turkey \\ Corresponding Author : nerken@sakarya.edu.tr \\ ORCID: 0000-0003-1546-0205
}

\section{Article Info:}

DOI: $10.22399 /$ ijcesen.590692

Received : 11 July 2019

Accepted : 23 September 2019

\section{$\underline{\text { Keywords }}$}

Milling

Surface roughness

Taguchi

ANOVA

\begin{abstract}
:
In this study, optimum machining conditions were determined by investigating the surface roughness of the 7075-T6 aluminum alloy milling, depending on the spindle speed (rpm), feed per tooth (Fz-mm/tooth) and the cooling type parameters. Taguchi experiment design method was used to save time and cost. Experiments were based on the Taguchi L16 orthogonal array and signal/noise $(\mathrm{S} / \mathrm{N})$ ratios were used in the evaluation of the test results. Optimum surface roughness values were determined with Taguchi optimization. In addition, variance analysis and regression analysis were performed. Confirmation tests were conducted to verify the work. As a result of the confirmation tests, it was found that the surface roughness optimization in the milling of the 7075-T6 aluminium alloy was successfully applied.
\end{abstract}

\section{Introduction}

As with all researches in machining processes, it is of great importance to determine the appropriate cutting conditions and cutting tool life in milling. In many studies, it is seen that the effects of factors such as material feature of milling part, type/ material of cutting tool, cutting depth, feed rate, speed number are examined.

Aluminium alloys with high strength/weight ratios, good corrosion/fatigue resistance and high metal removal rate constitute a large part of the workability of milling operations. AA 7075 T6 aluminium alloy, which is in light metals group, is widely used in aerospace, automotive and defence industry due to its low density, high hardness, strength and thermal properties. The machinability of this alloy is easier than the titanium and magnesium alloys in the same group.

Surface roughness is one of the most widely used quality characteristics in machining and the average and total surface roughness are the most commonly used roughness parameters. Studies in this area focus on the effects of cutting parameters (cutting speed, axial depth of cut, radial depth and feed rate), cutting tool geometry/material and workpiece material changes on surface roughness [1-4]. The Taguchi experiment design method is a successful method of solving optimization problems by increasing the number of experiments and processing performance at a low cost. The biggest advantage of the Taguchi method is that it can predict the result. The Taguchi method eliminates unnecessary experiments and saves time and costs. For these reasons lots of scientists have made studies on surface roughness optimization by Taguchi method as listed below.

Pillai et al. conducted an experimental study of optimization of surface roughness and machining time in milling of Al6005A alloy. They used Taguchi-Grey relational and ANOVA to investigate effects of parameters [5]. Parida et al. made a study about optimization of surface roughness in machining GFRP composite. They planned experiments according to L27 orthogonal array and found optimum levels of parameters by Taguchi method [6]. Tosun et al. studied the effect of cutting tool, spindle speed and feed rate on surface roughness of AA7075-T6 in milling process. The results indicated that the surface roughness was increased when feed rate was increased but the surface roughness was decreased when the spindle speed was increased [7]. Günay examined the optimization of AISI 316L austenitic stainless steel processing of the $\mathrm{Fc}$ and Ra cutting parameters and 
tool nose Radius. He performed the experiments using Taguchi method [8]. Pinar et al. investigated influences of cutting speed, feed rate, axial/radial depth of cut and nose radius and their two-way interactions on the surface roughness by Taguchi method in machining of AA5083-H36 alloy. They made an optimization using $\mathrm{S} / \mathrm{N}$ ratio and ANOVA [9]. In another study Mandal et al. conducted experimental work based on L9 orthogonal array with three parameters. These were depth of cut feed rate, cutting speed at three levels. They investigated machinability of AISI 4340 steel and found that depth of cut had maximum contribution on tool wear [10]. Kivak experimented to investigate the machinability of Hadfield Steel with PVD TiAlN and CVD TiCN/Al2O3-coated carbide inserts in dry milling conditions. He used the Taguchi method and regression analysis in his study. He selected cutting tool, cutting speed and feed rate as machining parameters. He obtained that feed rate had been the most effective parameter according to variance analysis [11]. Vishnu et al. made a study to investigate effects of type of machining conditions, cutting speed, feed rate, depth of cut, type of tool on surface roughness of EN-353 Alloy Steel in turning operation. They used L27 orthogonal array in experiments and ANOVA to dedicate influence of parameters. As a result they found that type of coolant had been the most effective factor [12].

Many factors affect the surface roughness, such as the type of material, cutting tool, cutting speed and progress, cutting depth, coolant and machine construction. As seen from literature survey surface roughness changes with one of these factors. However, the effects of the factors causing change can be different and independent, or they may be related to each other. In this experimental study for the best surface quality, experiments were designed with Taguchi experiment design and Taguchi optimization was applied to the obtained results.

\section{Experimental Work}

In the milling of AA7075 T6, dimensions 125x70x15 mm, 3-flutes cemented carbide end mills with 45 helical angles (Fig.1) produced by ISCAR were used. The diameter of the end mills were 12 $\mathrm{mm}$. The AA7075-T6 material used in the experiments is in plate form and dimensions of $125 \times 70 \times 15 \mathrm{~mm}$ and the chemical composition is given in Table 1. The alloy has $150 \mathrm{HB}$ hardness, 460-505 MPa yield strength, 530-570 MPa tensile strength, $10 \%$ elongation. The experiments were

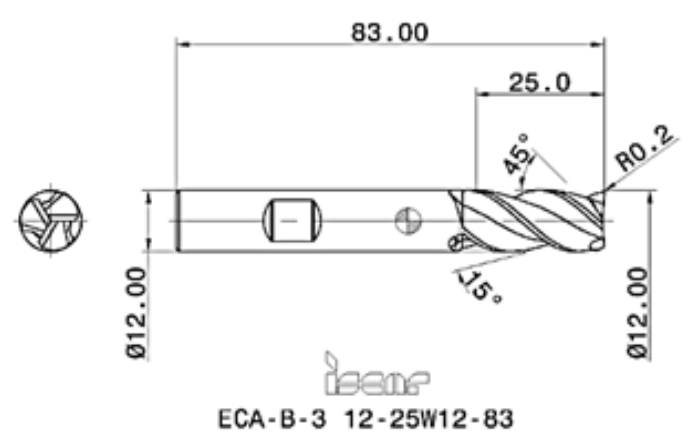

Figure 1. Cutting tool used in experiments

carried out at the Taksan TMC 700V CNC vertical machining center (Fig.2) in Sakarya University Engineering Faculty Mechanical Engineering Laboratory. CAM programs generated by CreoParametric 2.0 package program. Milling process of work piece are shown in Fig.3 and 4. In Fig. 3 cooling is generated by liquid and in Fig.4 cooling is generated by air.

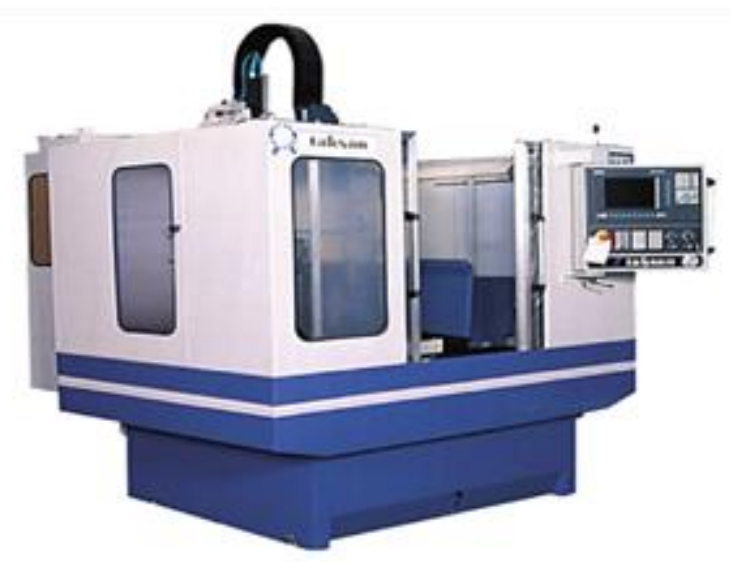

Figure 2. Taksan TMC 700V CNC vertical machining center

Surface roughness were measured after milling process. For measuring the surface roughness values the Mahr-Marsurf PS1 model desktop surface roughness tester was used (Fig.5). The meter measures according to DIN EN ISO 3274 standards. One point measurement was performed on the same axis from the workpiece. The cut length $(\mathrm{Lc})$ was 0.8 $\mathrm{mm}$ and the sampling length (Lt) was chosen as 5.6 $\mathrm{mm}$ for the measurements of the surface roughness values that occurred during machining on the workpiece. 
Table 1. Chemical composition of the material

\begin{tabular}{|l|l|l|l|l|l|l|l|l|l|l|}
\hline Element & $\mathbf{F e}$ & $\mathbf{S i}$ & $\mathbf{C u}$ & $\mathbf{M n}$ & $\mathbf{M g}$ & $\mathbf{Z n}$ & $\mathbf{C r}$ & $\mathbf{T i}$ & Other & Al \\
\hline \% Weight & 0.5 & 0.4 & $1.2-2$ & 0.3 & $2.1-2.9$ & $5.1-6.1$ & 0.21 & 0.2 & 0.15 & $87.1-94.7$ \\
\hline
\end{tabular}

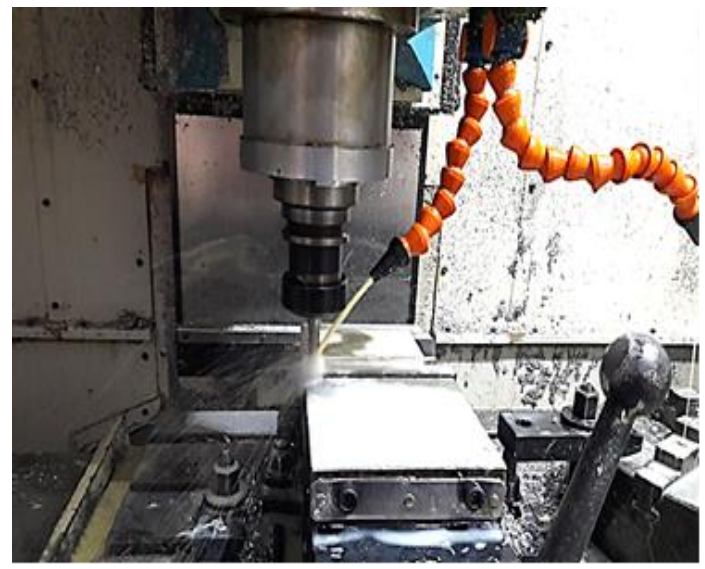

Figure 3. Milling process by cooling liquid

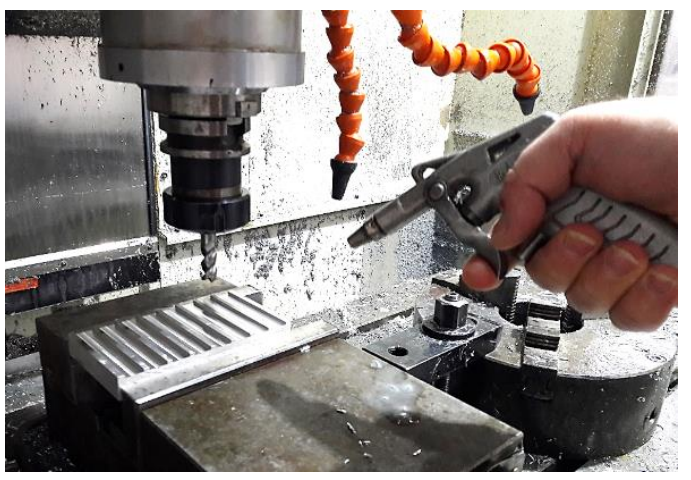

Figure 4. Milling process by cooling air

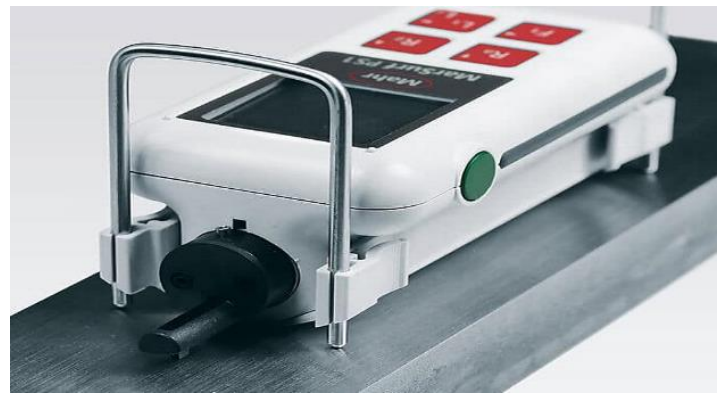

Figure 5. The Mahr-Marsurf PS1 model desktop surface roughness tester

\section{Taguchi Method}

In the 60s, the Taguchi method proposed by Genichi Taguchi has been widely applied because of its proven success in improving industrial product quality. Researchers' interest in the Taguchi method is increasing day by day, especially because of the low number of experiments, ease of application and easy evaluation of qualitative.
Taguchi Method is an experiment design and optimization method based on parameter design, system design and tolerance design. Most commonly used in statistical analysis of data collected within the scope of quality assurance systems. Taguchi's experimental design method is a very useful method to determine the optimum combination between different levels of different parameters.

Experiments are used by researchers to identify and understand a system or a specific process. An experiment in the literature is also a test. Observing and analysing the outputs of a process or system is the modification and analysis [13]. Experimental studies in engineering, product and process development play an important role. Experimental design was first introduced in the 1920 s by the famous British statistician R.A. Fisher and his friends.

Taguchi Method is an experiment design and optimization method based on parameter design. In its simplest sense, optimization can be defined as the optimal use of limited resources at hand. Optimization is very important in academic studies. Scientists use different optimization methods in their works [14-16]. In this study Taguchi method was chosen to optimize results. Most commonly used in statistical analysis of data collected within the scope of quality assurance systems. Taguchi's experimental design method is a very useful method to determine the optimum combination between different levels of different parameters. Moreover Taguchi method is a method used to save time and cost.

\section{Results}

In the experiments, three different parameters were selected. These are cooling type, spindle speed and feed per tooth. Four different levels were selected for each of the parameters and shown in Table 2. According to full factorial experiment design $4 \times 4 \times 2=32$ experiments were required. In Taguchi method orthogonal array is used to decrease experiment numbers. The most suitable orthogonal array L16 $\left(4^{2} \times 2^{1}\right)$ was selected to determine optimum conditions and analyze the parameters [17]. Thus Taguchi method reduced the experiment number $50 \%$. The experiments were planned according to the Taguchi's L16 orthogonal array. All statistical analyzes were performed using the 
Minitab 17 statistical package program at 95\% confidence level. Mean surface roughness measurements based on orthogonal array L16 are given in Table 3. Then, optimization was performed with the help of the obtained results. In this optimization process, there are three different functions, known as the Taguchi loss function, which are also referred to as the noise ratio $(\mathrm{S} / \mathrm{N}$ Signal/Noise) function. They are "the smallest is the best", "the highest is the best", "the nominal is the best" cases. We expect surface roughness to be low so in the experiments, "the smallest is the best" was accepted. The last column in Table 3 shows signal/noise ratios. In the case where the result called the performance characteristic is the smallest of the best, the formula shown in Equation 1 is used. Here $y_{i}=$ the observed data at the $i_{\text {th }}$ experiment and $\mathrm{n}=$ the number of the experiments.
Larger S/N ratio performs better to achieve optimum process parameter.

$$
\eta=\frac{S}{N}=-10 \log \left(\frac{1}{n} \sum_{i=1}^{n} \frac{1}{y_{i}^{2}}\right)
$$

According to the experimental results, $\mathrm{S} / \mathrm{N}$ ratio obtained is shown in Table 4 and plotted as shown in Fig.6. The optimal level of process parameters can be found by taking into account the highest $\mathrm{S} / \mathrm{N}$ ratio value. In the optimization of the cutting parameters, the optimum cutting parameters were found as A1B1C2. Here, the spindle speed (A1): $3000 \mathrm{rpm}$, feed per tooth (B1): $0.04 \mathrm{~mm} /$ tooth and cooling type (C2):liquid. Spindle speed graph looks like Pillai's results [5] and feed per tooth results are close to Gopal's [18] results.

Table 2. Parameters and levels

\begin{tabular}{|c|c|c|c|c|c|}
\hline Symbols & Parameters & Level 1 & Level 2 & Level 3 & Level 4 \\
\hline A & $\begin{array}{c}\text { Spindle speed } \\
(\mathrm{rpm})\end{array}$ & 3000 & 3500 & 4000 & 4500 \\
\hline B & Feed per tooth & 0.04 & 0.06 & 0.08 & 0.1 \\
\hline C & Cooling type & Air & Liquid & - & - \\
\hline
\end{tabular}

Table 3. The experimental layout for L16 orthogonal array

\begin{tabular}{|c|c|c|c|c|c|}
\hline $\begin{array}{l}\text { Experiment } \\
\text { Number }\end{array}$ & $\begin{array}{l}\text { Spindle } \\
\text { Speed (rpm) }\end{array}$ & $\begin{array}{l}\text { Feed per } \\
\text { tooth(mm/tooth) }\end{array}$ & $\begin{array}{l}\text { Cooling } \\
\text { type }\end{array}$ & $\begin{array}{l}\text { Surface } \\
\text { roughness }(\boldsymbol{\mu m})\end{array}$ & S/N (dB) \\
\hline 1 & 3000 & 0.04 & Air & 2.348 & -7.139 \\
\hline 2 & 3000 & 0.06 & Air & 3.445 & -10.743 \\
\hline 3 & 3000 & 0.08 & Liquid & 2.61 & -8.332 \\
\hline 4 & 3000 & 0.1 & Liquid & 3.456 & -10.771 \\
\hline 5 & 3500 & 0.04 & Air & 2.434 & -7.726 \\
\hline 6 & 3500 & 0.06 & Air & 3.558 & -11.024 \\
\hline 7 & 3500 & 0.08 & Liquid & 3.587 & -11.094 \\
\hline 8 & 3500 & 0.1 & Liquid & 3.826 & -11.654 \\
\hline 9 & 4000 & 0.04 & Liquid & 2.418 & -7.669 \\
\hline 10 & 4000 & 0.06 & Liquid & 3.475 & -10.819 \\
\hline 11 & 4000 & 0.08 & Air & 4.384 & -12.837 \\
\hline 12 & 4000 & 0.1 & Air & 4.99 & -13.962 \\
\hline 13 & 4500 & 0.04 & Liquid & 2.415 & -7.658 \\
\hline 14 & 4500 & 0.06 & Liquid & 3.616 & -11.164 \\
\hline 15 & 4500 & 0.08 & Air & 4.309 & -12.687 \\
\hline 16 & 4500 & 0.1 & Air & 4.776 & -13.581 \\
\hline
\end{tabular}




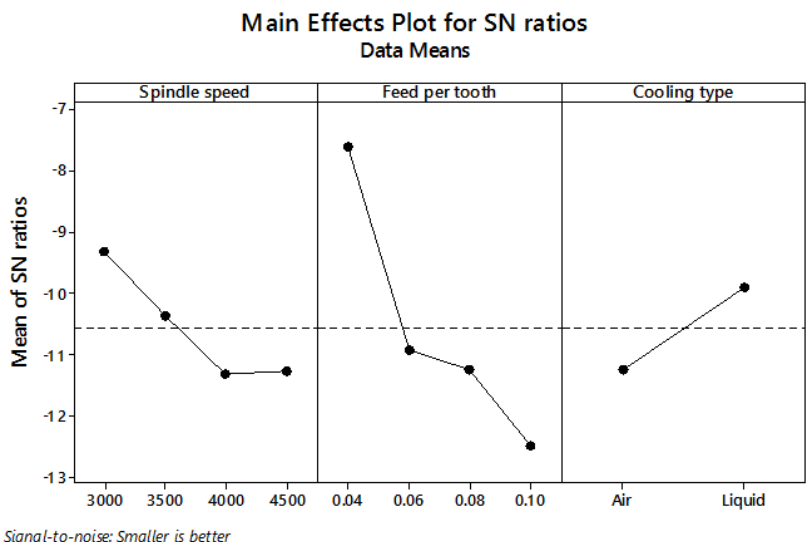

Figure 6. Mean of $S / N$ ratios

Table 4 shows the values of the effect order of the factors according to the "smallest best" signal noise ratios $(\mathrm{S} / \mathrm{N})$ to surface roughness by Taguchi analysis. As seen from Table 4 the dominant factor on the surface roughness is the feed per tooth and the second order is the spindle speed and third one is cooling type.

Table 4. S/N response table for surface roughness

\begin{tabular}{|c|c|c|c|}
\hline Level & $\begin{array}{l}\text { Spindle } \\
\text { speed }\end{array}$ & $\begin{array}{l}\text { Feed per } \\
\text { tooth }\end{array}$ & $\begin{array}{l}\text { Cooling } \\
\text { type }\end{array}$ \\
\hline 1 & -9.316 & -7.617 & -11.247 \\
\hline 2 & -10.375 & -10.938 & -9.896 \\
\hline 3 & $-11,322$ & -11.238 & - \\
\hline 4 & -11.273 & -12.492 & - \\
\hline Delta & 2.006 & 4.875 & 1.351 \\
\hline Rank & 2 & 1 & 3 \\
\hline
\end{tabular}

In order to check the distribution of the collected/calculated values of the results, the values given in Table 3 were confirmed by the probability graph in Fig.7. The plots were constructed for a confidence interval (CI) of $95 \%$. It is proved that the data points are roughly aligned with the middle straight line, $\mathrm{P}$ value is greater than 0.05 and $\mathrm{AD}$ statistics are low, so the drawn data is distributed normally. Based on this, these data can be used for optimization and experimental research [19].

\section{Analysis of Variance}

With variance analysis (ANOVA), the effects of which factors are effective on the process are determined statistically. In the analysis of variance, the aim is to determine the extent to which the factors examined affect, the output values selected in order to measure the quality and how the different levels cause the variability.

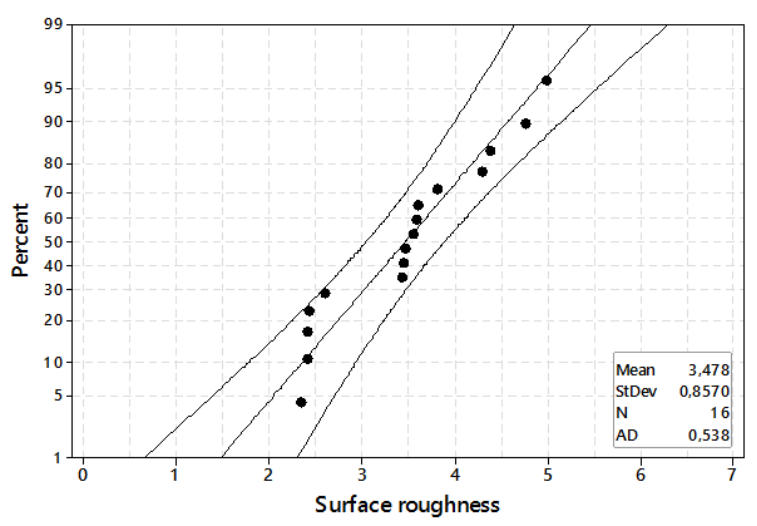

Figure 7. Probability plot of surface roughness

In this study, ANOVA was used to analyze the effects of feed per tooth, spindle speed and cooling type on surface roughness. In addition, the statistical reliability of the results obtained is also tested. In table the $\mathrm{S}$ : error variance is the percentage of variation in the response described by the R-Sq: model, while R-Sq (adj) is the percentage of variation corresponding to the response explained by the model, adjusted for the number of predictors in the model according to the number of observations.

The importance of control factors in ANOVA is determined by comparing the $\mathrm{F}$ values of each control factor. The last column of the Table 5 shows the percentage value of each parameter contribution, indicating the degree of impact on process performance. When the effect ratios on the mean surface roughness of the parameters were examined, the most important parameter was determined as the feed per tooth of $66.46 \%$ like Pınar's research [9]. Spindle speed and cooling type showed lower effect $17.6 \%, 13.29 \%$ respectively as seen from Table 5 .

\section{Regression Analysis of Surface Roughness}

Regression analysis is the analysis method used to measure the relationship between two or more variables [20]. Because of the different parameters in the study, regression analysis can be performed for surface roughness [21]. In this study, the dependent variable is surface roughness, whereas the independent variables are feed per tooth (ft), spindle speed (ss) and cooling type (ct). For the surface roughness, the estimated Equations 2 and 3 given below are obtained by regression analysis.

$R a=-0.422+0.000582 \mathrm{ss}+28.87 f t$

(cooling type $=$ air)

$R a=-1.027+0.000582 s s+28.87 f t$ (cooling

type=liquid) 
Table 5. ANOVA for surface roughness

\begin{tabular}{|c|c|c|c|c|c|}
\hline Source & DF & Adj SS & Adj MS & F value & Contribution rate \% \\
\hline $\begin{array}{c}\text { Spindle } \\
\text { speed }\end{array}$ & 3 & 1.939 & 0.646 & 17.83 & 17.604 \\
\hline $\begin{array}{c}\text { Feed per } \\
\text { tooth }\end{array}$ & 3 & 7.322 & 2.440 & 67.32 & 66.466 \\
\hline $\begin{array}{c}\text { Cooling } \\
\text { type }\end{array}$ & 1 & 1.464 & 1.464 & 40.40 & 13.295 \\
\hline Error & 8 & 0.290 & 0.036 & & 2.632 \\
\hline Total & 15 & 11.016 & & & 100 \\
\hline S= 0.0422, R-Sq=97.47 \%, R-Sq(adj)= 95.26\% \\
\hline
\end{tabular}

Equation 2 was used when the cooling type had been liquid and Equation 3 was used when the cooling type had been air. The actual test results obtained with the linear regression model and the estimated values are compared in Fig. $8 . \mathrm{R}^{2}$ of the equations which were obtained by the linear regression model for Ra were found to be $90 \%$.

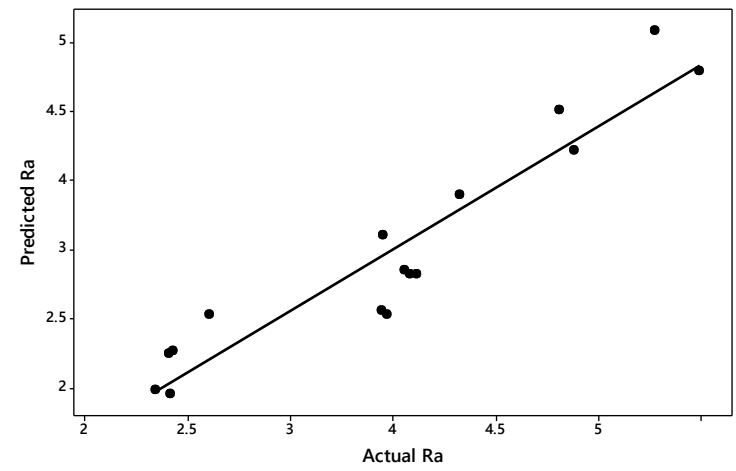

Figure 8. Comparison of the linear regression model with experimental results

\section{Confirmation}

In Taguchi method, after the determination of the variable levels that will give the optimum results, the verification tests are performed in which the accuracy of the optimization is tested. Optimum parameter levels for surface roughness according to $\mathrm{S} / \mathrm{N}$ ratios calculated with the smallest best one objective function were determined as A1 (spindle speed $=3000 \mathrm{rpm}$ ), B1 (feed per tooth $=0.04$ ) and C2 (cooling type=liquid) The last step of Taguchi method is to control optimum levels. So confirmation tests were performed with optimum levels. Confirmation test results are shown in Table 6. According to the difference between experimental result and prediction calculated error is $0.59 \%$. That means the optimization is successful.
Table 6. Confirmation test result

\begin{tabular}{|l|l|c|}
\hline & Prediction & Experimental \\
\hline Levels & A1B1C2 & A1B1C2 \\
\hline Parameters & 30000.04 Liquid & $\begin{array}{c}30000.04 \\
\text { Liquid }\end{array}$ \\
\hline $\begin{array}{l}\text { Surface } \\
\text { roughness } \\
(\boldsymbol{\mu m})\end{array}$ & 2.348 & 2.334 \\
\hline
\end{tabular}

\section{Conclusions}

In the present study, the effects of spindle speed, feed per tooth and cooling type process parameters on surface roughness in milling of 7075-T6 aluminium alloy were evaluated by means of Taguchi experiment design method. Accordingly, the following results were obtained:

According to the variance analysis, 95\% confidence level was found to be significant on the mean surface roughness of all process parameters. The most significant factor in the change of roughness with respect to $66.46 \%$ of the feed per tooth, this rate was followed by spindle speed with a ratio of $17.60 \%$ and the cooling type had an effect with a ratio of $13.29 \%$.

The optimum levels of the control factors for minimizing the surface roughness using $\mathrm{S} / \mathrm{N}$ rates were determined. The best average surface roughness value was $0.04 \mathrm{~mm}$ feed per tooth, at $3000 \mathrm{rpm}$ and 2.334 in liquid-cooled operation.

The improved linear regression model showed a very good relationship. $\mathrm{R}^{2}$ of the equations which were obtained by the linear regression model for $R_{a}$ were found to be $90 \%$. 
In this study, it was found that the Taguchi method was applied successfully to save time and cost in milling of 7075-T6 aluminium alloy. Obtained results can be used future academic researches and industrial applications.

\section{Acknowledgement}

The author would like to express their gratitude to Murat Ozsoy and ISCAR Turkey for cutting tools.

\section{References}

[1] Asilturk I, Neseli S, Ince MA, "Optimization of parameters affecting surface roughness of Co28Cr6Mo medical material during CNC lathe machining by using the Taguchi and RSM methods" Measurement. 78,120-128, 2016 DOI: 10.1016/j.measurement.2015.09.052

[2] Ozturk S, "Application of the Taguchi method for surface roughness predictions in the turning process" Materials Testing 58 (9), 782-787, 2016 DOI: $10.3139 / 120.110917$

[3] Uysal A, "Surface roughness in nano fluid minimum quantity lubrication milling of AISI 430 ferritic stainless steel" Journal of Testing and Evaluation 45, 933-939, 2017 DOI: 10.1108/ILT-10-2015-0141

[4] Zhang JZ, Chen JC, Kirby ED, "Surface roughness optimization in an end-milling operation using the Taguchi design method" Journal of Materials Processing Technology 184, 233-239, 2007 DOI: 10.1016/j.jmatprotec.2006.11.029

[5]Pillai JU, Sanghrajka I, Shunmugavel M, Muthuramalingam T, Goldberg M, Littlefair G, "Optimisation of multiple response characteristics on end milling of aluminium alloy using TaguchiGrey relational approach" Measurement 124, 291298, 2018

DOI: 10.1016/j.measurement.2018.04.052

[6]Parida AK, Routara BC, Bhuyan RK, "Surface roughness model and parametric optimization in machining of GFRP composite: Taguchi and response surface methodology approach" Materials Today: Proceedings 2, 3065-3074, 2015 DOI: 10.1016/j.matpr.2015.07.247

[7]Tosun N, Kuru C, Altıntaş E, Erdin OE, "Investigation of surface roughness in milling with air and conventional cooling method" Journal of Faculty of Engineering and Architecture of Gazi University 25,141-146, 2010

[8] Günay M, "Optimization with Taguchi method of cutting parameters and tool nose radius in machining of AISI 316L steel" Journal of the Faculty of Engineering and Architecture of Gazi University 28, 437- 444, 2013

[9] Pinar AM, Filiz S, Ünlü BS, “A comparison of cooling methods in the pocket milling of AA5083H36 alloy via Taguchi method" The International Journal of Advanced Manufacturing Technology 83, 1431-1440, 2016 DOI: 10.1007/s00170-015-7666-
[10]Mandal N, Doloi B, Mondal B, Das R, "Optimization of flank wear using Zirconia Toughened Alumina (ZTA) cutting tool: Taguchi method and regression analysis" Measurement 4, 2149-2155, 2011 DOI: 10.1016/j.measurement.2011.07.022

[11] Kivak T, "Optimization of surface roughness and flank wear using the Taguchi method in milling of hadfield steel with PVD and CVD coated inserts" Measurement 50, 19-28, 2014 DOI: 10.1016/j.measurement.2013.12.017

[12] Vishnu AV, Ramana MV, Tilak KBG, "Experimental investigations of process parameters influence on surface roughness in turning of EN-353 alloy steel under different machining environments" Materials Today: Proceedings 5, 4192-4200, 2018 DOI: 10.1016/j.matpr.2017.11.682

[13] Montgomery DC, "Design and Analysis of Experiments", Wiley, New York, 2007

[14] Recioui A, "Optimization of circular antenna arrays using a differential search algorithm" Acta Physica Polonica A 128,7-8, 2015 DOI: 10.12693/APhysPolA.128.B-7

[15] Ozsoy M, Kurnaz C, “An optimization study of a hydraulic gear pump cover with finite element method" Acta Physica Polonica A 132, 944-948, 2017 DOI: 10.12693/APhysPolA.132.944

[16] Filiz İH, Olguner S, Evyapan E," A study on optimization of planetary gear trains" Acta Physica Polonica A 132:728-733, 2017 DOI: 10.12693/APhysPolA.132.728

[17] Roy K R, “A Primer on the Taguchi Method”, Van Nostrand Reinhold, New York, 1990

[18]Gopal PM, Prakash KS, "Minimization of cutting force, temperature and surface roughness through GRA, TOPSIS and Taguchi techniques in end milling of $\mathrm{Mg}$ hybrid MMC" Measurement 116, 178-192, 2018 DOI: 10.1016/j.measurement.2017.11.011

[19]Ryan BF, Joiner BL, Cryer JD, MINITAB Handbook: Update for Release, Cengage Learning, 2012

[20]Cetin M H., Ozcelik B, Kuram E, Demirbas E,'Evaluation of vegetable based cutting fluids with extreme pressure and cutting parameters in turning of AISI 304L by Taguchi method" Journal of Cleaner Production 19, 2049-2056, 2011 DOI: 10.1016/j.jclepro.2011.07.013

[21]Kara F, "Taguchi optimization of surface roughness and flank wear during the turning of DIN 1.2344 tool steel" Materials Testing 59 (10) , 903-908, 2017 DOI: $10.3139 / 120.111085$ 